Proceedings of the New Zealand Grassland Association 49: 135- 140 ( 1988)

\title{
CHANGING SEASONAL GROWTH OF PASPALUM PASTURES BY OVERDRILLING RYEGRASS AND WHITE CLOVER
}

E. R. Thorn

Ruakura Dairy Research Centre, MA F, Hamilton

Abstract

Volunteer summer-growing paspalum is often present in dairy pastures of northern New Zealand. When paspalum becomes the dominant grass winter/spring pasture production is reduced. This creates management problems on seasonal dairy farms because cow feed requirements and milkfat production are highest in winter/spring

This paper gives data from a current experiment at Ruakura Agricultural Research Station in which Roundup" herbicide was used to provide a competition-free environment for the overdrilling of cool-season pasture species. Herbicide rates of 6, 4, 2 and 0 //ha were applied I" autumn 1965 before overdrilling a mixture of Ellett ryegrass and Grasslands Kopu white clover. A fitth treatment was the original pasture which was not sprayed or overdrilled.

High rates (4-6//ha) of Roundup completely eliminated paspalum from the pasture and immediately reduced the white clover to a low proportion (less than $10 \%$ of dry matter). The sprayed and overdrilled pastures have remained ryegrass dominant over the duration of the experiment. In 1985 and 1966, winter/spring production from the new ryegrass dominant pastures were significantly better than from the original paspalum dominant pasture.

The implications of the noticeable increase In paspalum In the renewed pastures are discussed.

Keywords: pasture renewal, pasture renovation, Roundup" herbicide, pasture botanical composition, seasonal pasture production.

\section{INTRODUCTION}

In northern New Zealand, volunteer paspalum (Paspalum dilatatum Poir.) is often a part of the perennial grass component of dairy pastures. Herbage production from paspalum is restricted to the warm season from October to April/May (Percival 1977). Pasture production during winter/spring is therefore reduced in paspalum-dominant pastures, which may be reflected in reduced cow performance in early lactation.

Pasture renewal should be considered where species like paspalum constitute greater than $25 \%$ of the pasture herbage (Thorn et a/. 1987). The rhizomatous paspalum offers severe competition to establishing cool-season species like perennial ryegrass when these are introduced by direct drilling. One way of reducing this competition is by blanket application of a non-selective herbicide before overdrilling.

This paper described 2 years of results from a current experiment which examined the effects of blanket application of glyphosate (Roundup@) herbicide and direct drilling of ryegrass and white clover on pasture composition and production.

The work reported here had 2 objectives:

(i) to measure the effect of contrasting rates of herbicide on the pasture botanical composition and seasonal pasture production.

(ii) to determine the stability of the pasture composition achieved by blanket spraying herbicide and direct drilling.

\section{MATERIALS AND METHODS}

Study area

The experiment was located at the Ruakura Agricultural Research Station. Ground frosts are common, averaging $34 \%$ of cool-season days (May-August). Dry spells during December-March are common, often accompanied by high day temperatures (screen maxima of $25^{\circ} \mathrm{C}$ or greater). 
Soils range from well-drained Bruntwood silt loams to imperfectly drained Te Kowhai silt loams. Annual maintenance dressing of $\mathrm{P}, \mathrm{K}$ and $\mathrm{S}$ have been applied as potassic superphosphate during the study period.

Pasture composition in summer was $40-50 \%$ paspalum and $10-15 \%$ ryegrass on a dry matter (DM) basis. Ryegrass comprised $50-60 \%$ and Poa spp. $10 \%$ of the pasture DM in spring. White clover ranged from $20-30 \%$ of DM throughout the year.

\section{Experimental design and treatments}

The treatments were original pasture and blanket spraying with $0,2,4$ and $6 l$ of Roundup@ in 200 l water/ha. Sprayed plots were direct drilled with a mixture of Ellett ryegrass $(18 \mathrm{~kg} / \mathrm{ha})$ and Grasslands Kopu white clover $(3 \mathrm{~kg} / \mathrm{ha})$. Treatment plots $(15 \times 31 \mathrm{~m})$ were arranged in a randomised block design with 6 replications.

Plots were sprayed on 12 March 1985 after 14 days regrowth, grazed again on 20 March, then cross-drilled using a Duncan triple disc drill. Half the above seeding rates were applied with each pass. A bar harrow was used to assist with seed coverage. Ninety-six percent of the sown Ellett ryegrass seedlings and $81 \%$ of the ryegrass plants in the original pasture contained the endophyte fungus Acremonium loliae. The presence of this fungus protects the plants from attack by Argentine stem weevil.

During the study period (March 1985 to April 1987), the plots were grazed by dairy cows on 22 occasions, the first 47 days after drilling. Average stocking densities of $160 \mathrm{cows} / \mathrm{ha}$ for 6 hours of grazing were used. Pre- and post-grazing herbage masses ranged from 2.5-2.8 $t$ DM/ha and 1.5-I .81 DM/ha, respectively.

\section{Sward measurements}

Botanical composition. Herbage in each plot was sampled by ground level clipping before dissection into ryegrass, Poa spp., paspalum, prairie grass, other grasses and weeds. Dead material from all species was bulked before drying all components at $100^{\circ} \mathrm{C}$ for 36 hours and weighing. Sampling was before spraying, after seedling emergence, and thereafter at 2- or 3-monthly intervals for the first and second years, respectively, at least 3 weeks following a grazing.

Tiller density. Ryegrass and paspalum tillers and white clover rooted nodes were counted in 5 randomly located quadrats (each $22 \times 3 \mathrm{~cm}$ ) per plot. Counts at 2- to 3-weekly intervals following grazing were made 2 or 3 monthly in the first and second years, respectively.

Seasonal growth rates and yields. Visual estimates of herbage mass were made at each grazing as described by Thorn et al. (1986). Seasonal yields were obtained by summing growth differences between post-grazing estimates and the following pre-grazing estimates for winter/spring (May-October) and summer/autumn (November-April)

\section{RESULTS}

Potential seedling densities were 1000 and 340 plants $/ \mathrm{m}^{*}$, respectively, for the sown ryegrass and white clover. These data were calculated taking into account seed weight, germination \% and sowing rates for the seedlines used. Seedling numbers in sprayed plots in May 1985 were 79 and $30 \%$ of potential for ryegrass and white clover, respectively. Comparable data for unsprayed plots were 45 and $21 \%$.

The effects of treatments on species proportions (\% of DM) are illustrated in Table 1. Statistical analyses showed that the effects of the 6 and $4 /$ ha herbicide rates were similar. Differences in the proportions of pasture species between the $0 / /$ ha and control treatments and between the 6 and 4 / /ha herbicide rates were small and generally not significant. Thus data for the $6 /$ /ha and $0 / /$ ha treatments are excluded. Other pasture species (prairie grass, weeds, Poa spp., other grasses) gave inconsistent treatment responses and were always less than $12 \%$ of DM. 
Table 1: The effect of sprayıng Roundup herbicide and overdrilling Ellett ryegrass and Kopu white clover on the paspalum. ryegrass, white clover and dead material orodortions (\% of DM) in the pasture.

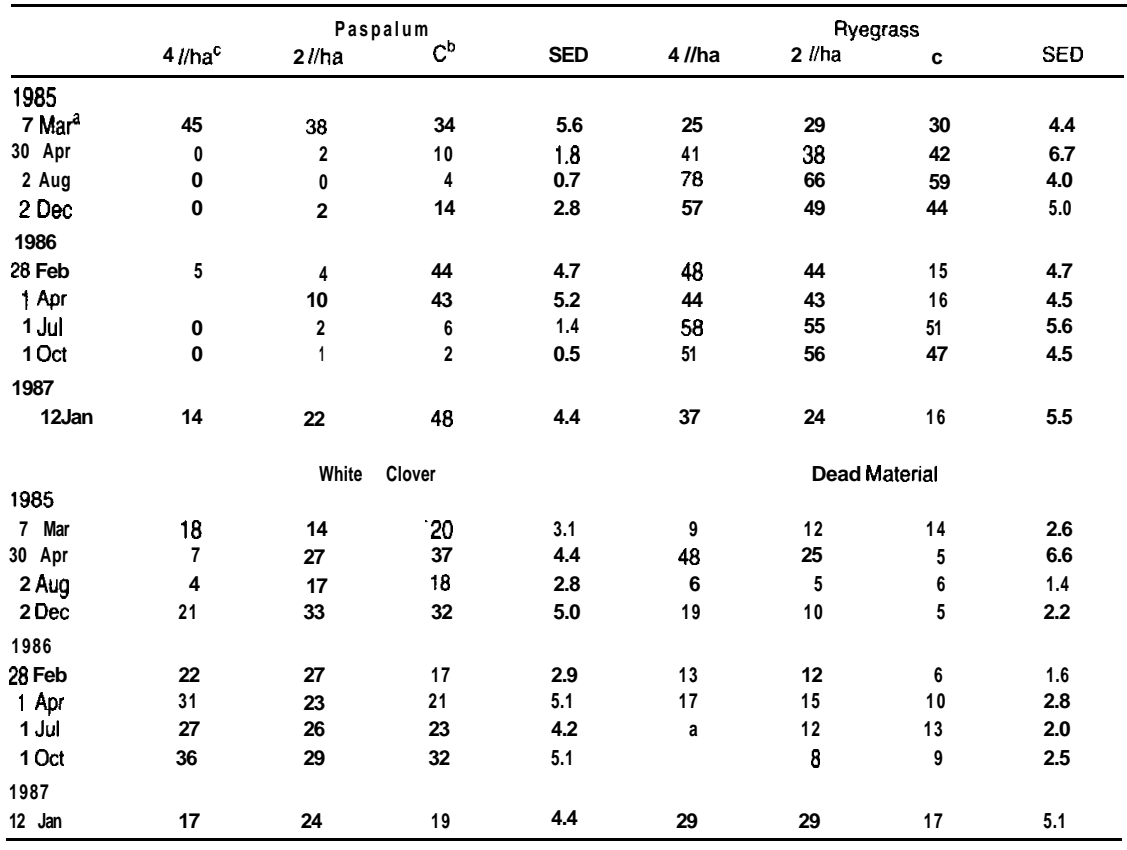

data obtained before spraying (12.3.85)

b $\mathrm{C}=$ original pasture (control)

$C_{\text {rate of Roundup }} \mathbb{\text { per hectare }}$

Table 2: Tiller density (tillers $/ \mathrm{m}^{2}$ ) for paspalum in sprayed and unsprayed plots in August 1985 , February 1986 and February 1987.

\begin{tabular}{lcccc}
1987. & & & \\
\hline Date & $4 / / \mathrm{ha}^{\mathrm{a}}$ & $2 / / \mathrm{ha}$ & $\mathrm{C}^{\mathrm{b}}$ & SED \\
\hline 29 Aug 1985 & 0 & 0 & 328 & 70.8 \\
10 Feb 1986 & 26 & 516 & 920 & 149.9 \\
9 Feb 1987 & 179 & 266 & 644 & 107.2 \\
\hline
\end{tabular}

9 Feb 1987

$\mathrm{a}=$ rate of Roundup-' per hectar

${ }^{b} \mathrm{C}=$ original pasture (control)

Paspalum was initially completely eliminated by the high rates (4-6 //ha) of Roundup@ herbicide and reduced to a low proportion by the low rate ( 2 Nha) (Table 1$)$. Noticeable increases in paspalum occurred in the sprayed pasures during the first and second summers following spraying and drilling. This was confirmed by tiller density data (Table 2). Paspalum generally decreased and ryegrass increased with increasing rates of herbicide (Table 1). White clover was reduced to a low proportion where high rates of Roundup@ were used. This effect persisted until the first summer following spraying, as from February 1986 there were no differences between treatments in clover levels (Table 1).

Dead material comprised almost half the pasture dry matter immediately after spraying with 4-6 Nha of Roundup ${ }^{\circledR}$ (Table 1). This effect had disappeared by August 1985 and during the following summer the new pastures contained more dead material than the original, but were always less than $20 \%$ of DM.

Growth rates for the period following spraying and drilling (29 March-6 May 1985) were 
on average much lower for the sprayed $(-23 \mathrm{~kg} \mathrm{DM} / \mathrm{ha} /$ day) than for the unsprayed plots (21 $\mathrm{kg} \mathrm{DM} /$ ha/day), reflecting plant death and subsequent loss of dry matter in the former owing to the effects of the herbicide. Subsequently, winter/spring growth rates were higher for the new pasture than for the original pasture. A similar trend was found in 1986 as Fig. 1 illustrates, although growth rates were much lower. Growth rates from September to November were similar for sprayed and unsprayed pastures in 1985 (63 v. $68 \mathrm{~kg} \mathrm{DM} / \mathrm{ha} /$ day) and in 1986 (52 v. $51 \mathrm{~kg} \mathrm{DM} / \mathrm{ha} /$ day). Growth rates for summer (1985186) (December to February), however, were higher for the original than for the renewed pasture. This trend was not evident in 1986/87, as growth rates for all pastures fell to less than $10 \mathrm{~kg} \mathrm{DM} / \mathrm{ha} /$ day in late January, and in March/April growth rates for the new pasture exceeded that of the original (Fig. 1). 1985/86 summer rainfall was $88 \%$ above average $(241 \mathrm{~mm})$ while in $1986 / 87$ it was $32 \%$ below average.

The above trends in seasonal growth rates are translated into pasture yield in Table 3.
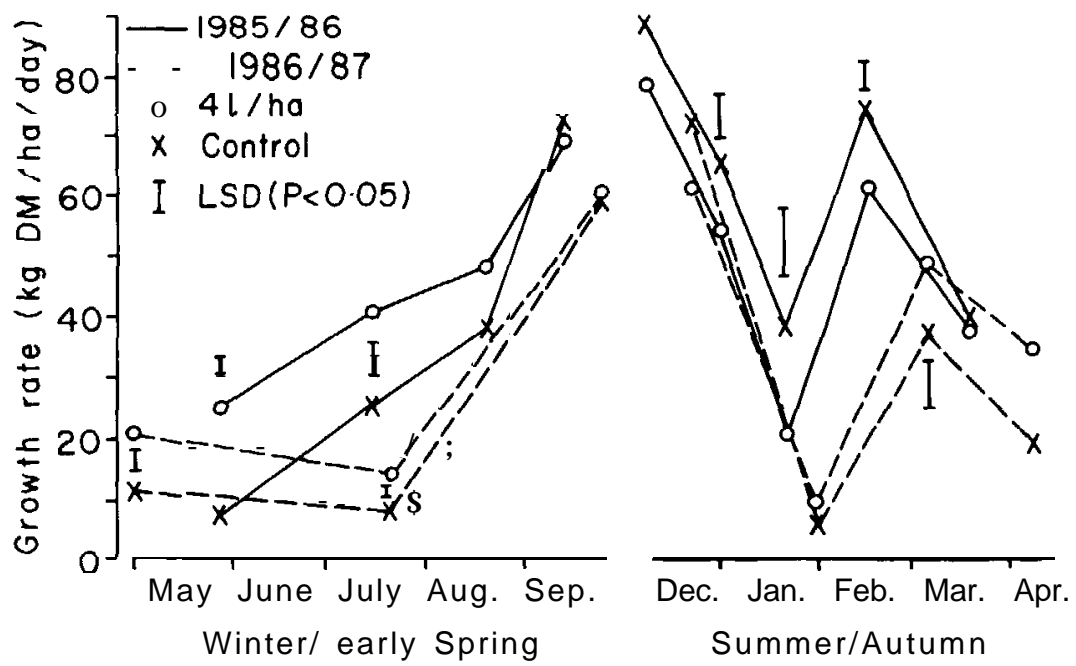

Figure 1: Growth rates (kg DM/ha/day) during winter/early spring and summer/autumn for the original pasture (control), and those receiving 4 //ha of Roundup" before overdrilling LSD $(P<0.05)$ are given where significant differences between treatments occurred.

Table 3: The effect on seasonal yields (t DM/ha) for 1985-87 of overdrilling Ellett ryegrass and Kopu white clover following spraying with Roundup" in March 1985.

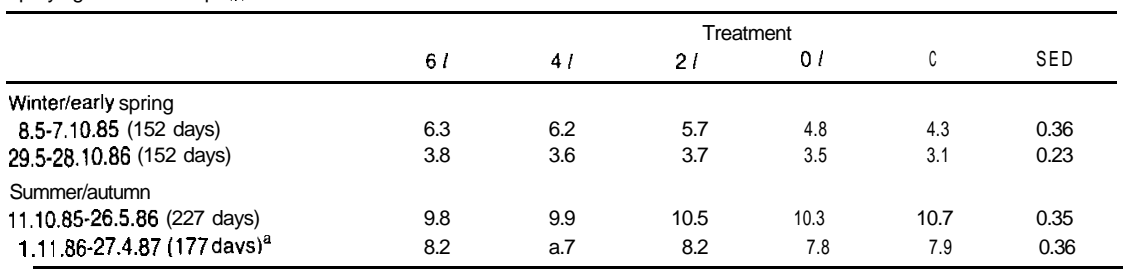

a incomplete 


\section{DISCUSSION}

Overdrilling perennial ryegrass after blanket application of Roundup ${ }^{(i)}$ herbicide rapidly changed the pasture from paspalum to ryegrass dominance (Table 1). The benefits of this change were immediately detected in improved winter/spring pasture production (Fig. 1, Table 3), since the summer growing species (paspalum) had been replaced by a winter/spring-growing species (perennial ryegrass). However, first-year winter/spring responses were approximately twice those that occurred in the second year, but the latter season was less favourable for growth. Thus the objective of providing more feed for the cows after calving (July) when their requirements and milkfat production are highest (Campbell \& Bryant 1978), has been achieved in each of the two years of this experiment. The sustained vigour of the new ryegrass-dominant pastures is indicated by their ability to produce similar summer/autumn yields to those of the unsprayed pastures (Table 3), even when rainfall was below average in the $1986 / 87$ summer.

An interesting feature of the experiment thus far is the re-infestation of the sprayed pastures with volunteer paspalum The rate of re-infestation seems to relate to the level of control achieved at spraying. Where 4 and 6 //ha of Roundup ${ }^{(\mathbb{B}}$ were used, paspalum was not detected until the first summer after spraying (February to April 1986) and by January 1987 a considerable amount of paspalum was present (14\% of DM) (Table 1). Visual assessments suggest that germination of resident paspalum seed was the main cause of this re-infestation. If the kill of resident paspalum was incomplete ( 2 l/ha treatment) then re-infestation rates were higher. The present trends indicate that pastures treated with 2 l/ha of Roundup ${ }^{\circledR}$ will reach a paspalum level of $20-25 \%$ of DM by the end of the second summer following treatment. Where 4-6 I/ha of Roundup ${ }^{(8)}$ has been used a further I-2 years may be required to reach this level, at which winter/spring pasture production begins to suffer (Thorn et al. 1987).

Despite detrimental effects of high rates of Roundup ${ }^{\circledR}$ on white clover growth, it had recovered to levels similar to those in unsprayed plots by February 1986 (Table 1). This recovery presumably reflects regrowth from surviving stolons of the resident clover, since the establishment and survival of Kopu white clover has been poor with an average density of only 12 plants $/ \mathrm{m}^{2}$ in April 1987 compared with 94 plants $/ \mathrm{m}^{2}$ in May 1985. This situation reflects the difficulty in establishing small-seeded species like white clover by direct drilling (Campbell 1972), especially if lack of moisture delays emergence (Hayes \& Williams 1986). Lack of moisture was probably important in the present experiment, since no substantial rainfall occurred until $23 \mathrm{~mm}$ of irrigation water was applied 21 days after drilling.

\section{Practical implications}

The experiment indicates that satisfactory control of paspalum can be achieved by blanket application of $4 \mathrm{l} / \mathrm{ha}$ of Roundup ${ }^{\circledR}$ herbicide, which is the current label recommendation. Ryegrass was then successfully introduced by direct drilling and has been maintained as the dominant grass species for the first and second years of this experiment. Further data from this experiment will indicate how long this situation can be maintained. However, because of the re-infestation of the pasture by paspalum, winter/spring pasture production could probably once again be improved by the implementation of the spray/drill procedure in 2-3 years' time. Currently, costs of establishing ryegrass pastures by the spray/drill method can be accounted for in terms of extra pasture grown and potential milkfat returns, in 1-2 years.

\section{Acknowledgements}

R.N. Gillespie, D.D. Wildermoth and M.J. Taylor for technical assistance and staff of the Dairy Research Centre, Ruakura, for help in execution of the experiment. Statistical advice and technical assistance were provided by N.R Cox and O.W. Aislabie, respectively. 


\section{References}

Campbell M.H. 1972. Pasture establishment. In Lazenby A.. Swain F.G. (Eds.). Intensive pasture production. Angus and Robertson Ltd.. Sydney.

Campbell A.G., Bryant A.M. 1976. Pasture constraints on dairy production. Proceedings Agronomy Society of NZ 8 115-116.

Hayes M.J., Williams E.D. 1966. Some effects of fluid-sowing. pre-germination. irrigation and soil covering on the establishment and growth of white clover slot-seeded into permanent pasture. Grass and Forage Science 41: 151-157.

Percival N.S. 1977. Survey of paspalum in New Zealand pastures. NZ Journal of Experimental Agriculture 5: 219.226.

Thorn E.R., Sheath G.W., Bryant A.M. 1986. Survival of overdrilled ryegrass in dairy pastures containing paspalum. Proceedings NZ Grassland Association 47: 141-I 46

Thorn E.R., Prestidge R.A.. Barker G.M. 1967. Pasture establishment on the dairy farm. Proceedings Ruakura Farmers' Conferenre 39: 50-52. 